\title{
The Physician Payment Sunshine Act
}

Clarification-In the second paragraph of this US Editor's choice (BMJ 2013;347:f4764, doi:10.1136/bmj.f4764), speaker compensation for continuing medical education (CME) events is listed as one of the forms of payment that will be reported to the Center for Medicare and Medicaid Services as part of the new Physician Payment Sunshine Act. Author José G Merino would like to clarify that reports are not required if the CME activity is accredited by the AACME, AAFP, ADA, AMA, or AOA; the manufacturer does not pay the speaker directly; and the drug or device manufacturer did not select the speaker or provide the CME organizer with a list of speakers.

Cite this as: BMJ 2013;347:44899

๑ BMJ Publishing Group Ltd 2013 